\title{
Pigmentation and spectral absorbance in the deep-sea arctic amphipods Eurythenes gryllus and Anonyx sp.
}

\author{
Hanne H. Thoen · Geir Johnsen · Jørgen Berge
}

Received: 12 February 2010/Revised: 28 June 2010/Accepted: 29 June 2010/Published online: 14 July 2010

(C) The Author(s) 2010. This article is published with open access at Springerlink.com

\begin{abstract}
As for many deep-sea animals, the red colouration of the two amphipods Eurythenes gryllus and Anonyx sp. has an important function providing camouflage, as the attenuation of the red wavelengths in seawater is higher than other colours within the visible range. Variation in colouration between different stages of colour intensity (related to size) is evident in both species. The red colour is caused by carotenoids, and the carotenoid composition was identified and quantified using spectral optical density signatures, high-performance liquid chromatography (HPLC) and liquid chromatography-mass spectrometry (LC-MS). The carotenoid astaxanthin was identified as the major carotenoid in both amphipods, both in pure and in esterified forms. In addition, minor amounts of lutein-like, canthaxanthin-like and several unidentified carotenoids were found in E. gryllus, while diatoxanthin, $\beta, \beta$-carotene and canthaxanthin-like carotenoids were detected in Anonyx sp. Generally, both species displayed an increase in the amount of carotenoids as a function of colour intensity and size. Shifts in $\lambda_{\max }$ in the OD (Optical density; dimensionless, acronym absorbance) spectra were evident in both species between the different colour stages in both the in vivo and the in vitro material, probably caused by changes in pigment composition. Similar shifts in $\lambda_{\max }$ were observed between
\end{abstract}

\footnotetext{
H. H. Thoen $(\square) \cdot$ G. Johnsen

Department of Biology, Norwegian University

of Science and Technology, 7491 Trondheim, Norway

e-mail: hannethoen@gmail.com

G. Johnsen · J. Berge

The University Centre on Svalbard,

P.O. Box 156, 9171 Longyearbyen, Norway

J. Berge

Akvaplan-niva, 9626 Troms $\varnothing$, Norway
}

the in vivo and in vitro pigment raw extracts in general, most likely caused by pigment-binding proteins. The differences in pigment composition and wavelength shifts suggest large intra- and inter-specific differences between the two species. Probable reasons for changes in pigment composition could be related to diet, season, moulting patterns, metabolic pathways and reproduction.

Keywords Carotenoids · In vivo absorbance $\cdot$ Deep-sea Amphipods · Camouflage · Arctic

\section{Introduction}

The red and orange colouration of many organisms and especially within the Crustacea are often caused by carotenoids, a group of fat-soluble pigments which are synthesized de novo in higher plants, mosses, bacteria, algae and fungi (Goodwin 1980; Gaillard et al. 2004), thereby making it available for other organisms through their diet. Carotenoids have various important biological functions regarding vision (Vershinin 1999), ovarian maturation (Dall et al. 1995), reproduction (Gilchrist and Lee 1972) and development (Petit et al. 1998; Berticat et al. 2000). One of the most common carotenoids in marine invertebrates is astaxanthin, which belongs to the xanthophylls and is usually formed through oxidative transformation from ingested $\beta, \beta$-carotene or zeaxanthin (Katayama et al. 1971; Tanaka et al. 1976). Astaxanthin has received a great deal of attention in the last couple of decades, due to its ability to act as an antioxidant and immunostimulant and thereby potentially play a role in the fight against human illnesses like cancer and cardiovascular diseases (Fraser and Bramley 2004; Higuera-Ciapara et al. 2006; Cornet et al. 2007). 
While one of the important functions of carotenoids in shallow water organisms is to prevent photodamage caused by solar radiation (Hairston Jr 1976; Bidigare et al. 1993; Schubert and García-Mendoza 2008), this obviously has no function in the deep-sea. However, carotenoids do serve an important function in the deep-sea in terms of camouflage (Herring 1972). Due to the exponential attenuation of sunlight with increasing depth, red wavelengths $(\sim 650 \mathrm{~nm})$ being the first to disappear and blue wavelengths ( $\sim 490 \mathrm{~nm}$ ) reaching depths around a 1,000 $\mathrm{m}$, a uniform distribution of red pigmentation in the exoskeleton of a deep-sea crustacean would provide valuable camouflage against predators (Herring 2002; Robison 2004; Johnsen 2005) both with regard to scattered surface light and by preventing reflection from bioluminescent light, which is a common trait in many deep-sea predators (Nicol 1958; Herring 1972).

Deep-sea scavenging amphipods (Crustacea, Malacostraca) feeding on carrion and detritus (Sainte-Marie 1992; Smith and Baco 2003) play an important role in the dynamics of the deep-sea food web by contributing to the decomposition and redistribution of large food falls (Hessler et al. 1978; Hargrave et al. 1994). One such scavenger is the necrophagous (feeding on carrion or corpses) lysiannassoid amphipod Eurythenes gryllus (Stoddart and Lowry 2004), which is one of the best studied species of deep-sea amphipods to this time. It is recorded in all major oceans (except the Mediterranean Sea), has a bentho-pelagic lifecycle, is found at depths down to 7,800 $\mathrm{m}$ (Ingram and Hessler 1983; Ingram and Hessler 1987; Thurston et al. 2002; Stoddart and Lowry 2004) and is a common member of the benthic mega-fauna found in deep-sea communities. Another lysiannassoid amphipod genus found in the deep-sea is Anonyx, which consists of mostly necrophagous scavengers which usually share the same role in the benthic community as E. gryllus, but are often found in shallower waters (Ingólfsson and Agnarsson 1999; Werner et al. 2004; Legeżyńska 2008). Both E. gryllus and Anonyx spp. occur in a range of colours, from white through different shades of orange and pink to a dark red colouration (Smith and Baldwin 1984). Earlier studies of E. gryllus have indicated an increase in colour intensity with age and sexual maturation (Smith and Baldwin 1984; Charmasson and Calmet 1987), but further research has yet to be published on this topic. Some Anonyx species, such as A. nugax (Obermüller et al. 2005), have a yellow or orange colouration, although this may vary between individuals. While the greatest species diversity of Anonyx occurs in the North Pacific (Steele 1979), which is also its place of origin, Arctic and North Atlantic waters show a much lower species diversity, probably due to slow dispersion. The morphological similarity of the species in this genus makes them difficult to identify, and many species have remained unrecognized for a long time (Steele 1979).

Most of the carotenoids found in deep-sea animals originate in phytoplankton in the surface layer and are subsequently transferred down through the food web (Herring 1972) or as suspended particulate matter containing unaltered carotenoids as reported by Repeta and Gagosian (1984) in 1,500 m depths off the Peruvian coast.

Although a few larger species have been known to act as predators, attacking weak or vulnerable prey items, most deep-sea amphipods are usually regarded as scavengers on detritus or carrion, which would most likely be where they obtain their carotenoids (Ingram and Hessler 1983; Smith and Baldwin 1984; Sainte-Marie and Lamarche 1985). Sainte-Marie and Lamarche (1985) found that among large Anonyx spp., normal food items included carrion, large copepods such as Calanus, which is an abundant genus in Arctic waters (Falk-Petersen et al. 2009), polychaetes and small crustaceans including euphausiids, mysids, cumaceans and amphipods. Wlodarska-Kowalczuk et al. (2004) reported a higher biomass of macrofauna in the ice-free areas outside Kongsfjorden in Svalbard, compared to other areas in the Arctic basin which were covered by multi-year ice, with a dominance of polychaetes and bivalves together with several species of crustaceans. This indicates a high availability of food items for amphipods in this area, either as carrion or as prey, and hence a reliable source of carotenoids.

The main aim of this study was primarily to identify and quantify the pigment composition in E. gryllus and Anonyx sp. Additionally, we aimed to explore the relationship between size, pigmentation and the corresponding in vivo and in vitro spectral absorbance characteristics within each species as well as any interspecific differences.

\section{Materials and methods}

The samples were collected at approximately $1,200 \mathrm{~m}$ depth, off the continental shelf outside the entrance of Kongsfjordrenna $\left(79^{\circ} 04.87^{\prime} \mathrm{N}\right.$; $\left.007^{\circ} 52.72^{\prime} \mathrm{E}\right)$ in WestSpitsbergen, Svalbard (Fig. 1) during two cruises with R/V "Jan Mayen", the first trap deployment at 19th of August 2007 (traps on seafloor for 6 days) and the second trap deployment at 23rd of August 2008 (traps on seafloor for 4 days).

The traps were constructed using PVC tubes converted into traps by placing an inverted funnel in one end and a mosquito net in the other end. The traps were attached to a frame and filled with dead polar cod (between 4 and 10 polar cod per trap) before they were deployed. Recovery of the traps was carried out by the help of an acoustic releaser (IXSEA, Oceano 2500) and flotation buoys. 

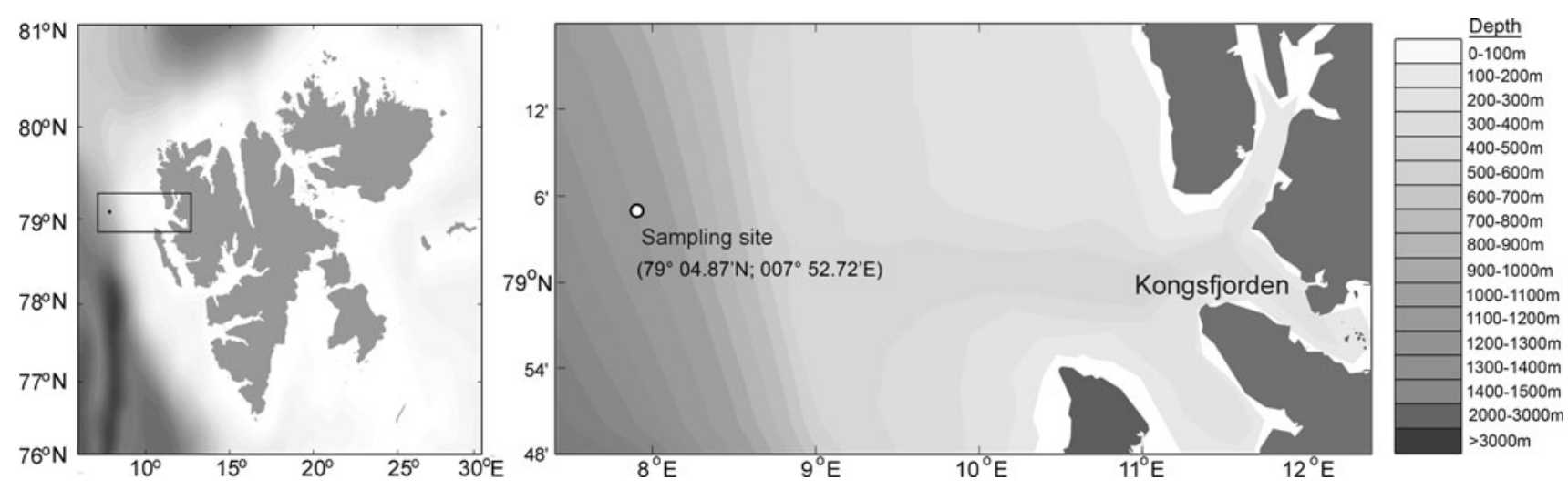

Fig. 1 Map over Konsfjordrenna, Svalbard

The temperature at $1,200 \mathrm{~m}$ depth was about $-0.8^{\circ} \mathrm{C}$ and the salinity at $34.9 \mathrm{PSU}$, indicating cold Atlantic water.

The collected material comprised two species, Eurythenes gryllus and Anonyx sp. The former is a cosmopolitan deep-sea species previously recorded from both the Arctic and Antarctic (Premke et al. 2003; De Broyer et al. 2004; Stoddart and Lowry 2004), whereas the latter is a species known only from the Svalbard region that has yet to be described (Berge, personal communication). Unfortunately, due to a clean-up in a biofreezer, approximately $3 / 4$ of the collected specimens of $E$. gryllus was lost. The rest of the specimens were then size-fractioned according to the following description.

The two species were split into discrete colour groups as a compromise between sample size and information about colour intensity (Figs. 3, 4). In addition, the body length (in $\mathrm{cm})$ of each amphipod from each colour stage was recorded. One-way analysis of variance (one-way ANOVA) and Tukey's HSD (honestly significant differences) were used for the statistical analysis.

The shell and/or tissue used for extraction were weighed using a Sauter AR 1014 weight with $\pm 0.001 \mathrm{~g}$ accuracy before measurements were taken. Optical density was used to describe spectral differences from 350 to $700 \mathrm{~nm}$ in vivo and in vitro. The term "absorption" $\left(\mathrm{m}^{-1}\right)$ is only used in general terms throughout the paper.

Four different methods were used to analyse the pigments in exoskeleton and muscle tissue:

1. In vivo $\mathrm{OD}(\lambda)(350-700 \mathrm{~nm})$ on pieces of exoskeleton was obtained using a quartz cuvette in a split-beam mode spectrophotometer (Jenway 6715 UV/Vis. Spectrophotometer) according to Grzymski et al. (1997).

2. In vitro OD $(\lambda)(350-700 \mathrm{~nm})$ of raw pigment extracts from each specimen was obtained using a quartz cuvette in a double-beam spectrophotometer (Unicam UV 500 Thermospectronic spectrophotometer). Pigment raw extracts were made by grinding the exoskeleton and/or muscle tissue in a mortar in an organic solvent, methanol for E. gryllus and 7:3 methanol: acetone for Anonyx sp., respectively. The extracts were left in dark for $24 \mathrm{~h}$ in a $-18^{\circ} \mathrm{C}$ freezer and then filtered through a $0.2-\mu \mathrm{m}$ filter (13-mm syringe filter, Minisart RC 25) to avoid debris and corresponding light scattering.

3. High-performance liquid chromatography (HPLC) using a Hewlett-Packard 1100 series HPLC system equipped with a diode array detector (350-800 nm) obtaining OD $(\lambda)$ according to the method of Rodrìguez et al. (2006) was used to isolate, identify and quantify the pigments present in the raw pigment extracts.

4. LC-MS (liquid chromatography-mass spectrometry) was performed according to the method of Stafsnes et al. (2010) on an Agilent time of flight (TOF) mass spectrometer equipped with an Agilent 1100 series HPLC system equipped with a diode array detector to determine the molecular weight of the carotenoids and thereby help in the identification process. Specifications were $\pm 3 \mathrm{ppm}$ error range and 10,000 in resolution.

The quantitative determination of the HPLC-isolated pigments in each colour stage was calculated using the response factor calculated from standards and the integrated area of the peaks at $440 \mathrm{~nm}$ in the chromatogram according to Eq. 1,

$\frac{\mathrm{ng}}{\mu \mathrm{l}_{\mathrm{extract}}}=\frac{\left(\operatorname{area}_{\lambda} \times \mathrm{Rsf}_{\lambda}\right)}{V_{i}}$

where $\frac{\mathrm{ng}}{\mu \mathrm{l}_{\text {extract }}}$ is nanogram pigment per microlitre extract, 'area ${ }_{\lambda}$ ' is the integrated area from each peak of the HPLC chromatogram, $\operatorname{Rsf}_{\lambda}$ is the response factor from the respective wavelength of the area and $V_{i}$ is the injected volume in $\mu \mathrm{l}$ in the HPLC. The results from Eq. 1 were then calculated into ' $\mu \mathrm{g} /$ total extract' and divided by the wet weight to obtain $\mu \mathrm{g} / \mathrm{g}$ wet weight. Response factors were calculated from standards; astaxanthin had an $\operatorname{Rsf}_{440}$ 
at 0.222 , cantaxanthin had an $\operatorname{Rsf}_{440}$ at $0.164, \beta, \beta$-carotene had an $\operatorname{Rsf}_{440}$ at 0.084 and lutein had an $\operatorname{Rsf}_{440}$ at 0.161 . The $\operatorname{Rsf}_{440}$ at 0.693 of diatoxanthin was calculated by the method of Jeffrey et al. (1997) in Eq. 2,

$E_{\text {diatoxanthin }}^{1 \%}=\frac{E_{\text {diadinoxanthin }}^{1 \%} \times \mathrm{MW}_{\text {diadinoxanthin }}}{\mathrm{MW}_{\text {diatoxanthin }}}$.

\section{Results}

Sample material

Despite similar set-up for the sampling, it was a marked difference in species composition between the 2 years. In 2007, all specimens caught ( $\sim 500$ individuals) consisted exclusively of E. gryllus. In 2008, however, all specimens ( 400-500 individuals) belonged to Anonyx sp., with the exception of one single individual of E. gryllus. It was evident from the sampled material that some of the specimens of E. gryllus had undergone moulting inside the traps, since there were several empty exoskeletons among them. This was not detected for Anonyx sp.

\section{Size}

The results from the measurements of body length are presented in Table 1. A 2.2 fold increase in length in E. gryllus from colour stages I to IV was evident, while there was an increase in length from colour stages I to III in Anonyx sp. of 1.48. When performing an ANOVA on the body lengths of $E$. gryllus, there was a significant difference $(F(3,8)=81.12, P<0.001)$ between the body length of the different colour stages. A Tukey's HSD test showed that there was a significant difference $(P<0.005)$ between the mean body lengths of colour stages I and II, stages I and III, stages I and IV, stages II and III and stages II and IV, while there was no significant difference $(P>0.05)$ between colour stages III and IV. The ANOVA in Anonyx sp. showed a significant difference $(F(2,6)=$ 28.60, $P<0.001)$ between the body lengths of the different colour stages, while the Tukey's HSD test showed a

Table 1 Mean body length $(\mathrm{cm}) \pm \mathrm{SD}$ of E. gryllus and Anonyx sp. in each colour stage

\begin{tabular}{lll}
\hline Colour stage & \multicolumn{2}{l}{ Body length $(\mathrm{cm}) \pm \mathrm{SD}$} \\
\cline { 2 - 3 } & E. gryllus & Anonyx sp. \\
\hline I & $3.03 \pm 0.20$ & $2.77 \pm 0.25$ \\
II & $4.37 \pm 0.41$ & $3.83 \pm 0.15$ \\
III & $6.07 \pm 0.25$ & $4.10 \pm 0.26$ \\
IV & $6.67 \pm 0.35$ & \\
\hline
\end{tabular}

$n=3$ in all colour stages

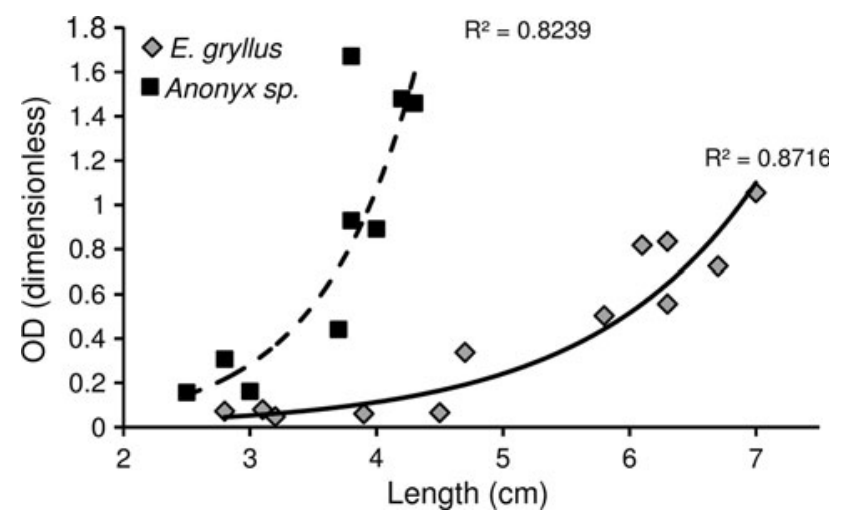

Fig. 2 Length versus OD with $R$-values in E. gryllus and Anonyx sp. indicating a exponential relationship between body length and colour intensity

significant difference $(P<0.005)$ between the mean body length of colour stages I and II and colour stages I and III, but no significant difference $(P>0.05)$ between colour stages II and III. The relationship between the in vitro OD $(\lambda)$ and body length of $E$. gryllus $\left(R^{2}=0.8716\right)$ and between the in vitro OD $(\lambda)$ and body length of Anonyx sp. $\left(R^{2}=0.8239\right)$ is displayed in Fig. 2.

In vivo $\mathrm{OD}(\lambda)$ characteristics

The measurements of in vivo OD $(\lambda)$ in pieces of exoskeleton in E. gryllus indicated that there was at least one carotenoid present with spectral characteristics similar to that of astaxanthin and with a stronger spectral signature as a function of colour intensity (Fig. 3a). In Anonyx sp., the results were not as clear due to the fact that the pigments were located both in the exoskeleton (minor amounts) and in the muscle tissue within (major amounts). Only pieces of exoskeleton were measured with the "in vivo technique", because the tissue was too soft to use, but both tissue and exoskeleton were included in the extraction of pigments. However, although the results were variable, the spectral characteristic from the in vivo OD $(\lambda)$ measurements did indicate carotenoids, with astaxanthin as the possible major pigment (Fig. 4a). Shifts in OD $\lambda_{\max }$ between the different colour stages in the in vivo measurements of exoskeleton were observed both in E. gryllus and in Anonyx sp. In E. gryllus, OD $\lambda_{\max }$ occurred at $487 \mathrm{~nm}$ in colour stage I and at $493 \mathrm{~nm}$ in colour stage IV. In Anonyx sp., OD $\lambda_{\max }$ was at $452 \mathrm{~nm}$ in colour stage I and at $455 \mathrm{~nm}$ in colour stage III.

In vitro OD $(\lambda)$ characteristics

As in the in vivo measurements, the in vitro OD $(\lambda)$ characteristic measurements of the pigment raw extracts in E. gryllus indicated that the main carotenoid was astaxanthin with a clear trend of increasing amounts of 

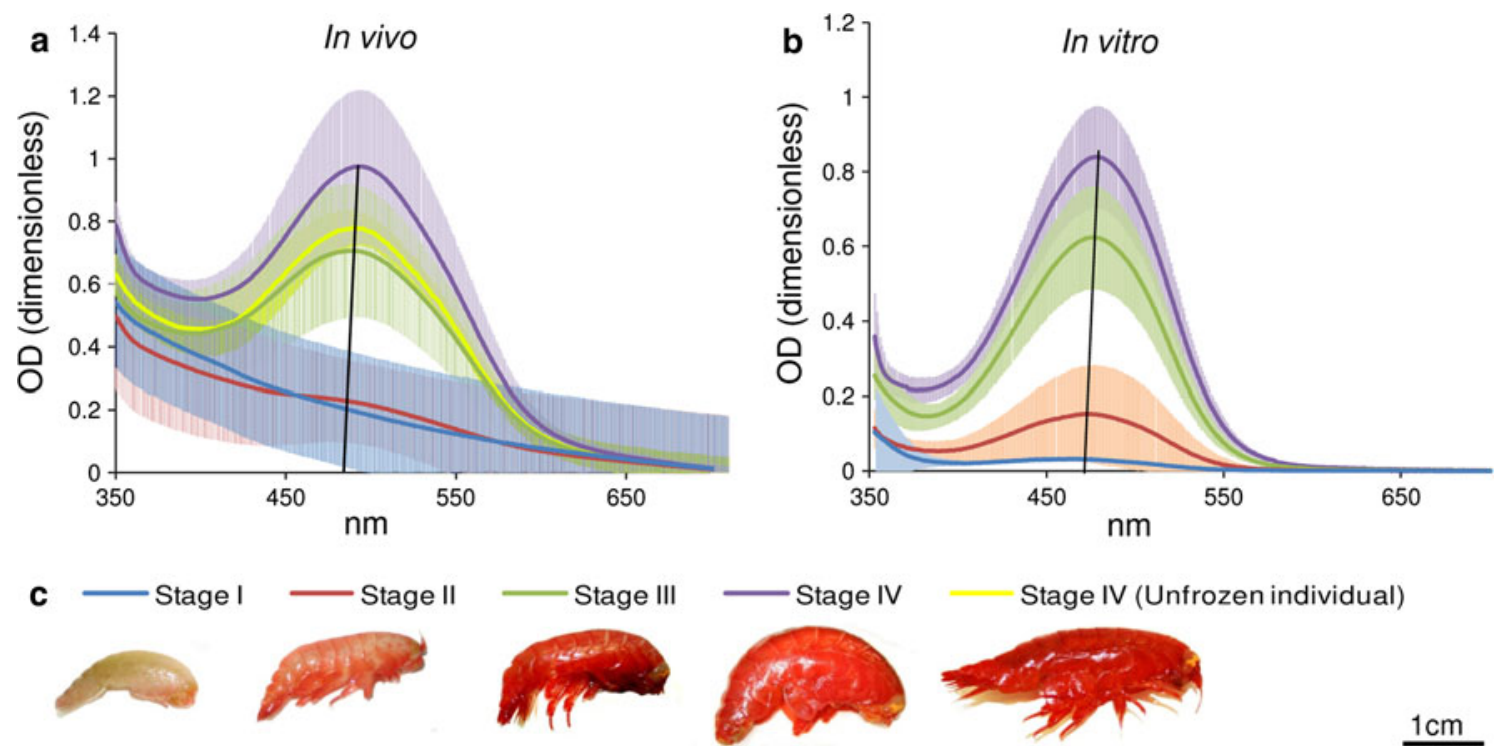

Fig. 3 a In vivo OD $( \pm \mathrm{SD})$ of pieces of exoskeleton from each stage of colour in E. gryllus. OD $(\lambda)$ indicates a stronger signature of astaxanthin as a function of colour intensity. Shifts in $\lambda_{\max }$ between the different colour stages are indicated by the line. $\mathbf{b}$ In vitro OD $( \pm \mathrm{SD})$ of raw pigment extracts of the whole exoskeleton of E. gryllus

in each stage of colour. OD $(\lambda)$ indicates stronger signature of astaxanthin as a function of colour intensity. Shifts in $\lambda_{\max }$ between the different colour stages are indicated by the line. $\mathbf{c}$ Colour stages for E. gryllus
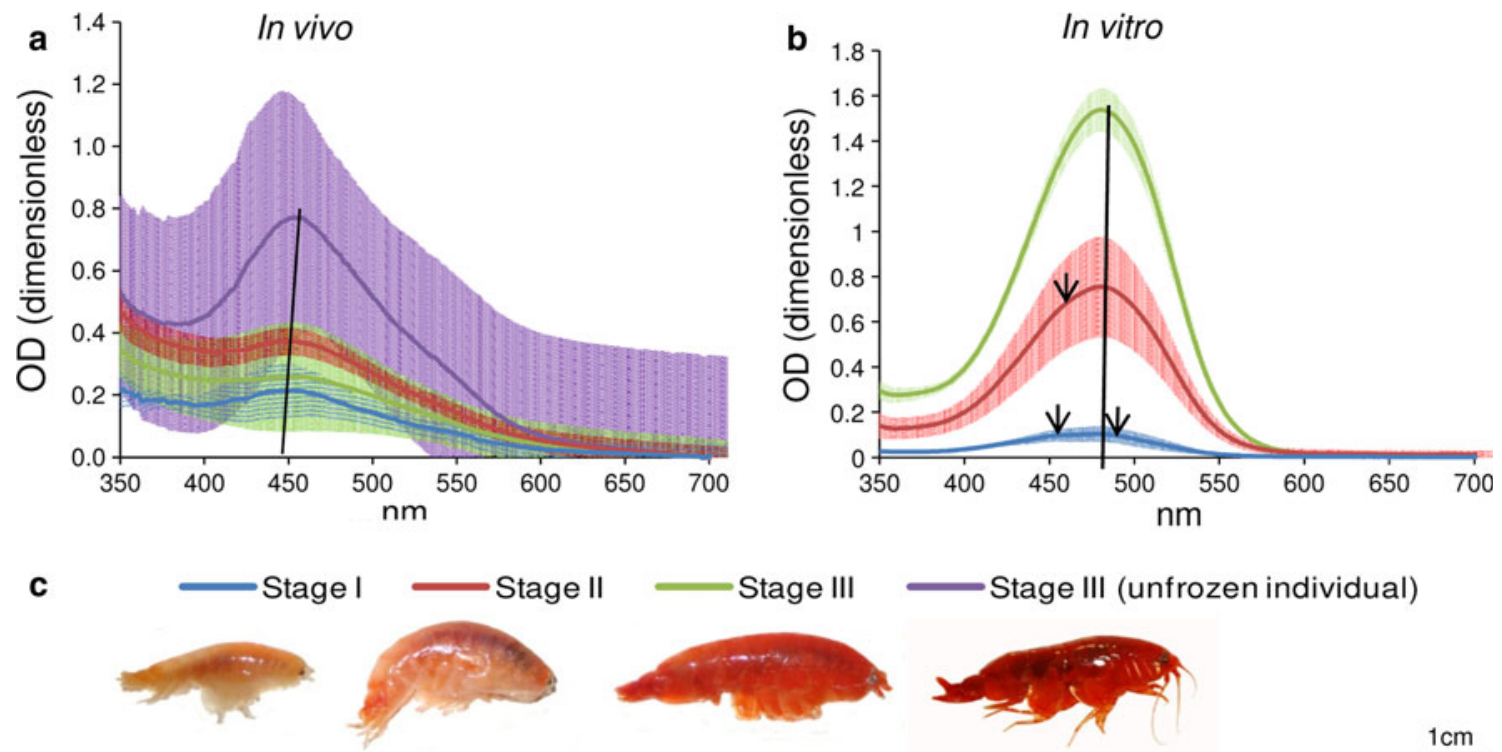

Fig. 4 a In vivo OD $( \pm$ SD) of pieces of exoskeleton from each stage of colour in Anonyx sp. Shifts in $\lambda_{\max }$ between the different colour stages are indicated by the line. $\mathbf{b}$ In vitro OD $( \pm \mathrm{SD})$ of raw pigment extracts of the whole exoskeleton and muscle tissue from Anonyx sp.

carotenoids as a function of colour intensity (Fig. 3b). In Anonyx sp., the OD $(\lambda)$ characteristics also indicated an astaxanthin-dominated signature, but a change in shape of the OD $(\lambda)$ between the different stages of colour indicated a mix of several pigments, which could occur in different amounts between the different stages of colour. It was also evident that the amount of carotenoids increased as a in each stage of colour. OD $(\lambda)$ indicates stronger signature of astaxanthin as a function of colour intensity. Arrows indicate shoulders. Shifts in $\lambda_{\max }$ between the different colour stages are indicated by the line. c Colour stages for Anonyx sp.

function of colour (Fig. 4b). As with the in vivo measurements, there were shifts in OD $\lambda_{\max }$ between the colour stages in the in vitro raw pigment extracts in E. gryllus and Anonyx sp. OD $\lambda_{\max }$ in E. gryllus at colour stage I was at $463 \mathrm{~nm}$, while in colour stage IV OD $\lambda_{\max }$ occurred at $478 \mathrm{~nm}$. In Anonyx sp., OD $\lambda_{\max }$ of colour stage I was at $479 \mathrm{~nm}$, while OD $\lambda_{\max }$ in colour stage III was at $480 \mathrm{~nm}$. 
Spectral shifts in OD $\lambda_{\max }$ between average in vivo and in vitro material

When comparing the average of in vivo and in vitro OD $(\lambda)$ from all colour stages, it was evident that there was a shift in $\lambda_{\max }$ from $486 \mathrm{~nm}$ in vivo to $476 \mathrm{~nm}$ in vitro in E. gryllus (Fig. 5a), which is a decrease in $\lambda_{\max }$ of $10 \mathrm{~nm}$. On the other hand, there was a shift in $\lambda_{\max }$ from $453 \mathrm{~nm}$ in vivo to $480 \mathrm{~nm}$ in vitro in Anonyx sp. (Fig. 5b), which is an increase in $\lambda_{\max }$ of $27 \mathrm{~nm}$. In both species, however, it was clear from plotting the difference spectra $(a(\lambda)-b(\lambda)=$ $c(\lambda)$ ) that the in vivo materials have wider absorption window than in vitro.

Variability in OD in the samples from E. gryllus and Anonyx sp. is displayed in Table 2. The CV was usually not higher than $20-30 \%$ of mean value.

\section{HPLC}

The results from the pigment isolation by HPLC are compiled in Table 3, and an example of a HPLC chromatogram from colour stage II in Anonyx sp. is displayed in Fig. 6. The pigments were identified by comparisons with standard pigment-specific elution times and their corresponding OD $(\lambda)$ characteristics. The major pigment fraction in both E. gryllus and Anonyx sp. was identified as
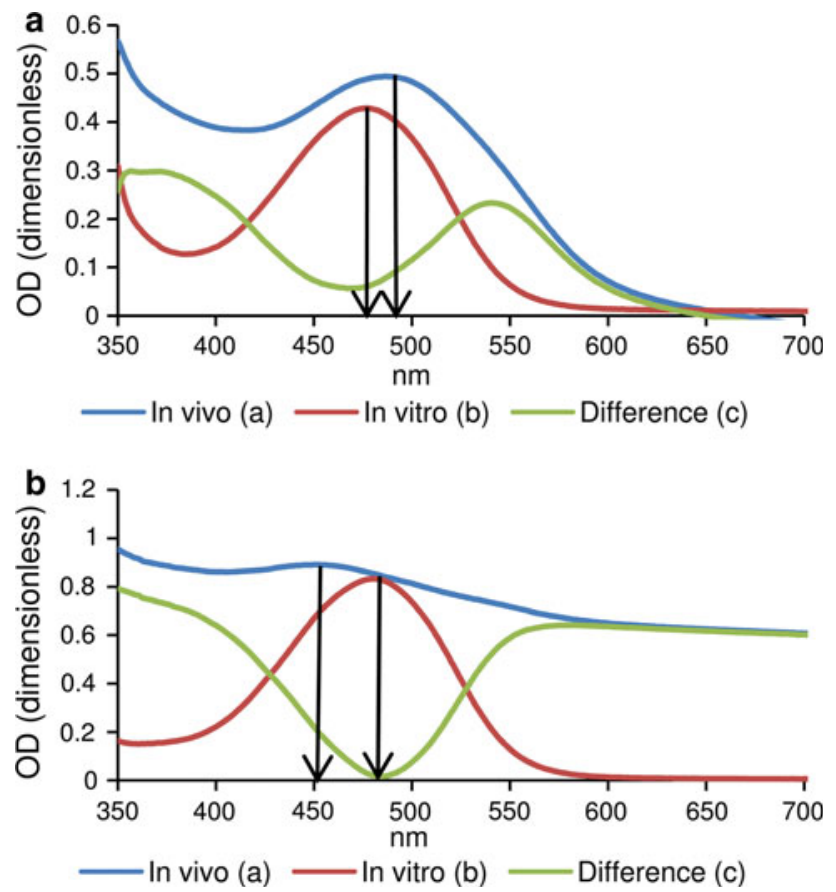

Fig. 5 a In vivo $(a)$ and in vitro $(b)$ OD $(\lambda)$ and the difference between them $(c)$ in E. gryllus. $(a(\lambda)-b(\lambda)=c(\lambda))$. b In vivo $(a)$ and in vitro $(b)$ OD $(\lambda)$ and the difference between $(c)$ in Anonyx sp. $(a(\lambda)-b(\lambda)=c(\lambda))$
Table 2 OD $\lambda_{\max }$ and variation in E. gryllus and Anonyx sp. at different colour stages in both in vivo and in vitro measurements

\begin{tabular}{|c|c|c|c|c|c|}
\hline & \multirow[t]{2}{*}{ Colour stage } & \multicolumn{2}{|c|}{ In vivo } & \multicolumn{2}{|c|}{ In vitro } \\
\hline & & $\lambda_{\max }$ & $\mathrm{CV}(\%)$ & $\lambda_{\max }$ & $\mathrm{CV}(\%)$ \\
\hline \multirow[t]{4}{*}{ E. gryllus } & I & 487 & 20.71 & 463 & 20.77 \\
\hline & II & 487 & 16.03 & 471 & 84.54 \\
\hline & III & 487 & 20.29 & 476 & 21.85 \\
\hline & IV & 493 & 18.02 & 478 & 15.71 \\
\hline \multirow[t]{3}{*}{ Anonyx sp. } & I & 452 & 21.85 & 479 & 33.51 \\
\hline & II & 453 & 13.43 & 480 & 29.41 \\
\hline & III & 455 & 8.58 & 480 & 6.22 \\
\hline
\end{tabular}

astaxanthin, and it appeared predominant in all colour stages.

Eurythenes gryllus: Only astaxanthin was found in colour stage I of E. gryllus. In colour stage II, astaxanthin was still predominant, together with a lutein-like carotenoid. Colour stage III had, in addition to astaxanthin, a canthaxanthin-like carotenoid together with traces of three other carotenoids with OD maxima situated around $467 \mathrm{~nm}, 458-488 \mathrm{~nm}$ and 454-482 nm. However, the amounts of the unknown carotenoids were too small to identify them with any certainty [OD maxima lower than 5 mAU (milli-absorbance unit, absorbance $=$ optical density (dimensionless))]. Colour stage IV had three forms of astaxanthin, a canthaxanthin-like carotenoid together with three unidentified carotenoids with OD maxima situated around $463 \mathrm{~nm}, 469 \mathrm{~nm}$ and 451-480 nm. The amount of astaxanthin I increased by a fourfold from colour stage I to stage IV in E. gryllus. There was a higher amount of astaxanthin I in colour stage III compared to stage IV.

Anonyx sp.: Anonyx sp. generally had a higher diversity of carotenoids than E. gryllus; in colour stage I, four forms of astaxanthin, two forms of diatoxanthin and $\beta, \beta$-carotene were present. There were two dominating forms of astaxanthin, one at $21 \mathrm{~min}$ (astaxanthin I) and one at $26.5 \mathrm{~min}$ (astaxanthin II, Fig. 6). The two forms were present in all the following colour stages. In colour stage II, astaxanthin I and II were present, together with two other forms of astaxanthin. In addition, there were three different forms of $\beta, \beta$-carotene, two forms of diatoxanthin and a cantaxanthin-like carotenoid, together with one unidentified carotenoid with OD max at $467 \mathrm{~nm}$. Colour stage III had both astaxanthin I and II together with four other forms of astaxanthin, two forms of a cantaxanthin-like carotenoid, one $\beta, \beta$-carotene-like carotenoid and one unidentified carotenoid with OD maxima situated around 456-480 nm. Astaxanthin I increased 4.16 times from colour stage I to stage III, while astaxanthin II increased 4.23 times from colour stage I to stage III. 
Table 3 Carotenoid composition in E. gryllus and Anonyx sp. $\mu \mathrm{g} / \mathrm{g}$ wet weight and the corresponding \pm SD are shown for each pigment stage (I-IV)

\begin{tabular}{|c|c|c|c|c|c|c|c|}
\hline \multirow[t]{4}{*}{ Carotenoids } & \multicolumn{7}{|c|}{ Carotenoid composition $(\mu \mathrm{g} / \mathrm{g}$ wet weight $\pm \mathrm{SD}$ ) } \\
\hline & \multicolumn{4}{|c|}{ Eurythenes gryllus } & \multicolumn{3}{|l|}{ Anonyx sp. } \\
\hline & \multicolumn{4}{|l|}{ Colour stages } & \multicolumn{3}{|l|}{ Colour stages } \\
\hline & I & II & III & $\mathrm{IV}^{*}$ & I & II & III \\
\hline Astaxanthin I & $9.40 \pm 3.15$ & $24.27 \pm 21.34$ & $72.20 \pm 15.28$ & $37.91 \pm 11.20$ & $5.85 \pm 2.55$ & $12.75 \pm 8.51$ & $24.35 \pm 3.97$ \\
\hline Astaxanthin II & - & - & - & - & $7.16 \pm 5.19$ & $18.35 \pm 4.66$ & $30.03 \pm 7.20$ \\
\hline Astaxanthin-like & - & - & - & $5.66 \pm 1.63$ & $2.77 \pm 2.14$ & $4.28 \pm 1.93$ & $9.90 \pm 2.84$ \\
\hline$\beta, \beta$-carotene & - & - & - & - & $0.65 \pm 0.10$ & $0.30 \pm 0.15$ & $0.05 \pm 0.01$ \\
\hline Diatoxanthin & - & - & - & - & $2.71 \pm 0.97$ & $2.88 \pm 1.16$ & $2.55 \pm 0.16$ \\
\hline Cantaxanthin-like & - & - & $1.70^{\mathrm{a}}$ & $2.09 \pm 0.81$ & - & $0.79 \pm 0.11$ & $1.17 \pm 0.18$ \\
\hline Lutein-like & - & $1.50^{\mathrm{a}}$ & - & - & - & - & - \\
\hline Unidentified compounds & - & - & Trace & Minor & - & Trace & Trace \\
\hline
\end{tabular}

$n=3$ in each colour stage

* Sources of error: not completely in solution, $\mathrm{H}_{2} \mathrm{O}$ in the extract (affects extraction efficiency), weight affected by high $\mathrm{H}_{2} \mathrm{O}$

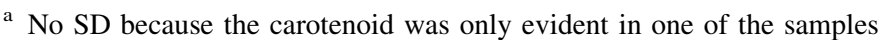

Fig. 6 HPLC chromatogram $(\mathrm{mAU}=$ milli $\mathrm{OD}$ at $440 \mathrm{~nm})$ from colour stage II of Anonyx sp. Retention times are displayed in minutes. Different pigment peaks and shoulders denote a given pigment attached to unspecific macro-molecules that slightly affects the mobility (polarity), cf. astaxanthin I as an example

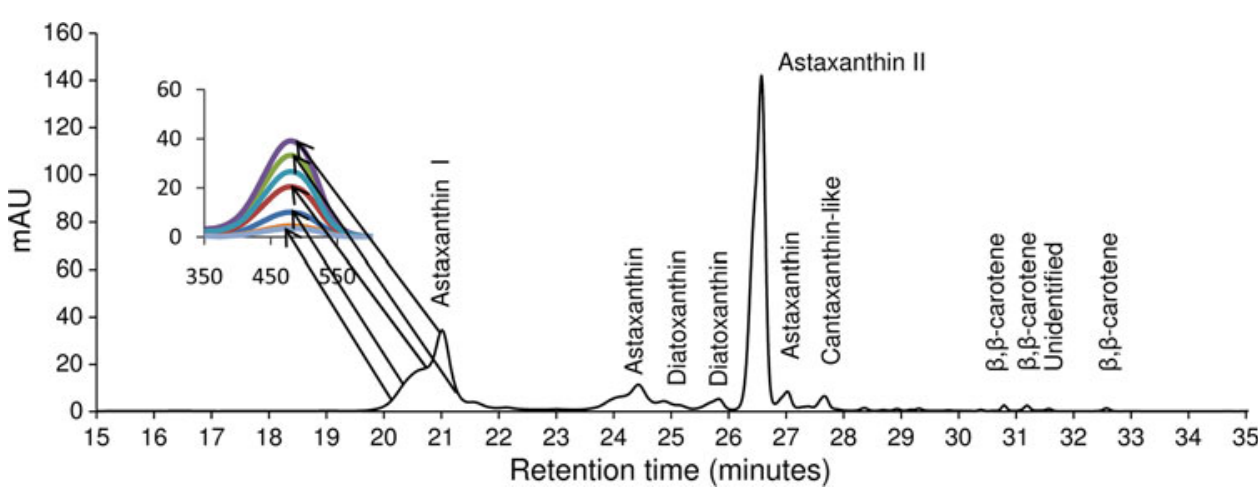

\section{LC-MS}

To verify pigment composition based on HPLC pigmentspecific retention times and $\mathrm{OD}(\lambda)$ characteristics of standards, the corresponding pigment extracts were analysed in LC-MS (liquid chromatography-mass spectrometry) to obtain the molecular weights. Astaxanthin has according to the literature a molecular weight of 596.85 (Jeffrey et al. 1997). The standard astaxanthin in the LC-MS appeared at approximately $13.6 \mathrm{~min}$, with a molecular weight at 596.39. The results from the LC-MS confirmed that the major pigment in both species was astaxanthin, with a molecular weight of 597.39 (since the LC-MS adds one proton, the molecular weight is about 1 higher than the average molecular weight). Astaxanthin occurred in all colour stages of both E. gryllus and Anonyx sp. at approximately $13.8 \mathrm{~min}$. The other large elution peak of pigment in Anonyx sp. appeared at approximately $15.61 \mathrm{~min}$ and had the same OD $(\lambda)$ characteristics as astaxanthin, but with a lower molecular weight of 577.52.
In the contour plot from the LC-MS results, both E.gryllus and Anonyx sp. displayed substances that had some OD in the range from 250 to $350 \mathrm{~nm}$, which is UV light, but these were not identifiable and not of carotenoid origin.

\section{Discussion}

Pigment composition

The results from the LC-MS chromatogram were compared with the results from the HPLC chromatogram to give a better indication of which pigments were present in the sample based on pigment-specific molecular weights. This confirmed that astaxanthin was the major carotenoid in all colour stages in both E. gryllus and Anonyx sp., which was indicated by the in vivo and in vitro OD measurements (Figs 3, 4, 5). The HPLC measurements indicated that there were several other carotenoids present both in colour stages II, III and IV of E. gryllus and in all colour 
stages of Anonyx sp., although these were not detectable in the results from the LC-MS due to low amounts and less sensitivity in the LC-MS than in the HPLC. Still, by the use of retention time and spectral comparisons with standards, the HPLC results identified, in addition to the various forms of astaxanthin, a lutein-like and a canthaxanthin-like form in E. gryllus and $\beta, \beta$-carotene, diatoxanthin and a canthaxanthin-like form in Anonyx sp. In all of the results from the HPLC, the retention times of the samples were lower than the retention times of the standards. This was evident in astaxanthin, diatoxanthin, $\beta, \beta$-carotene and the canthaxanthin-like carotenoid and was probably due to unknown molecules which were bound to the carotenoids. There were also different retention times between the HPLC and the LC-MS due to different mobile phase composition.

Astaxanthin is often found in a variety of forms due to the two hydroxyl groups which can attach to a variety of ester linkages and thereby increase the number of possible forms (Bidigare et al. 1993), and this was evident both in the samples from E. gryllus and from Anonyx sp. While at most two forms of astaxanthin were found in E. gryllus, Anonyx sp. had a total of six forms in colour stage III. In the LC-MS results from Anonyx sp., the molecular weight of the second large top (at $15.58 \mathrm{~min}$ ) of astaxanthin had a molecular weight of 577.52 with an $\lambda_{\max }$ at $482 \mathrm{~nm}$. The low molecular weight could indicate that this form of astaxanthin was degraded.

When preparing the pigment extracts from the amphipods, it became clear that E. gryllus and Anonyx sp. contain their pigments in different locations. This difference in keeping the pigments either in the exoskeleton (E. gryllus) or in the muscle tissue (Anonyx sp.) indicates that even though the two species probably have very similar lifestyles, they still have evolved quite differently in terms of pigment-bonding sites. The high $\mathrm{CV}$ of the in vitro measurements in colour stage II of E. gryllus was probably due to a shortage of material, which led to one specimen being more pigmented than the two others during grouping of the specimens.

The higher amounts of astaxanthin in colour stage III compared to colour stage IV in E. gryllus did not correspond to the results obtained in the in vitro raw pigment extracts from the spectrophotometer, where the carotenoid content increased as a function of colour intensity. The calculations and measurements of pigments per wet weight may, however, been affected by two sources of error; first of all, while the wet weight of E. gryllus was measured on the exoskeleton only, this was not possible in Anonyx sp. due to problems with size of specimens and loss of material during weighing. This resulted in the whole body of Anonyx sp. being used in the weighing, which could be affected by factors like water and stomach content.
Secondly, the weight of the exoskeleton in the specimens from colour stage IV in E. gryllus was almost twice that of the weights in colour stage III, possibly due to thickening of the exoskeleton with size and age or water contained in the pieces of exoskeleton. When calculating the $\mu g_{\text {pigment }} /$ $\mu \mathrm{g}_{\text {wet }}$ weight, this would have influenced the calculations quite substantially.

Difficulties with the in vivo OD readings in the spectrophotometer, due to uneven pigmentation and differences in thickness of the exoskeleton pieces, was probably the reason for the variability in the measurements of in vivo pieces of exoskeleton in Anonyx sp., both regarding the higher amount of pigment in the unfrozen material compared to the frozen and that colour stage II exhibited more pigmentation than colour stage III.

An increase in pigmentation was evident when the in vitro OD was plotted as a function of length, in which both E. gryllus and Anonyx sp. had an exponential increase. There was also a significant difference in length between the colour stages with the least colouration (I and II) in both E. gryllus and Anonyx sp. This apparent correlation between colour intensity and size (length) could indicate that there is an increase in pigmentation with growth and increasing body size. In contrast, the difference in length between colour stages III and IV in E. gryllus and colour stages II and III in Anonyx sp. was not significant. This may indicate that growth ceases or slows down at a certain size, while the amount of pigmentation continues to increase.

\section{Spectral shifts between colour stages}

Spectral shifts in the OD $\lambda_{\max }$ between the different colour stages occurred in both in vivo and in vitro measurements in both species. In the in vivo measurements, E. gryllus displayed a shift of $6 \mathrm{~nm}$ between colour stages I and IV, while Anonyx had a difference of $3 \mathrm{~nm}$ between colour stages I and III. In the in vitro measurements, E. gryllus had $15 \mathrm{~nm}$ between colour stages I and IV, while only $1 \mathrm{~nm}$ separated colour stages I and III in Anonyx sp. These shifts were probably caused by changes in pigment composition between different colour stages and indicate both intra- and inter-specific differences.

Spectral shifts between average in vivo and in vitro measurements

The spectral shifts between the averaged in vivo and in vitro measurements were probably caused by pigments being bound to proteins, which were present in the in vivo material, but removed when the pigments were extracted. Interestingly, in E. gryllus, the shift went from long wavelengths in the in vivo measurements to shorter wavelengths in the in vitro measurements, while in Anonyx 
sp. the shift went from shorter wavelengths in the in vivo measurements to longer wavelengths in the in vitro measurements, indicating interspecific differences.

\section{Changes in pigment composition}

The change in pigment diversity in the different stages of colour and body size in both E. gryllus and Anonyx sp. could be caused by uptake of carotenoids from different sources throughout the life of the amphipod. Ingram and Hessler (1983) and Smith and Baldwin (1984) found a relationship between increasing altitude above the seafloor and the average size of E. gryllus, which could indicate changes in diet throughout life. This could also help explain the advantage of the colour variation; younger individuals which spend most of their time close to the bottom would benefit from having a pale colour to blend in with the sediment, while larger individuals which spend more time higher up in the water column would be better camouflaged with a dark red colour. The diet may also be influenced by seasonal changes, since, as mentioned introductorily, most carotenoids in the deep-sea originate from phytoplankton found in surface waters $(<100 \mathrm{~m})$ and are transferred down the food web; seasonal changes in phytoplankton composition will subsequently influence carotenoid availability further down the food web. Baldwin and Smith (1987), on the other hand, suggested that carotenoid pigments accumulate during the intermoult period but are then lost again when moulting, leading to changes in pigment composition due to longer intermoult period in larger individuals (Ingram and Hessler 1987). This could again be influenced by the fact that organisms tend to live longer and grow to larger sizes in polar areas, a phenomenon often referred to as "Polar Gigantism" (Chapelle and Peck 1999). However, this would not be applicable to Anonyx sp., in which the majority of pigments are stored in the muscle tissue and are therefore not lost during moulting. Species-specific differences in metabolic pathways could be another explanation for changes in pigment composition between stages of body size, which causes one carotenoid to synthesize into another, as for example, $\beta, \beta$-carotene into astaxanthin, a well-known pathway in Crustacea (Tanaka et al. 1976; Berticat et al. 2000; Gaillard et al. 2004). Changes related to reproduction may also be likely, as carotenoids have been connected to several biological processes (Gilchrist and Lee 1972; Berticat et al. 2000; Liñán-Cabello et al. 2002) that could lead to changes in carotenoid composition between immature and mature females. Hargrave et al. (1994) suggested that due to increasing gonad volume taking up internal body volume during sexual maturation and breeding, feeding may actually be impossible in mature female amphipods. This was found to be the case in several
Anonyx spp. by Sainte-Marie and Lamarche (1985) and would probably influence the carotenoid composition in the amphipods quite substantially.

It was evident from the presence of several empty exoskeletons that some specimens of E. gryllus had undergone moulting in the traps. This, however, was not found among the specimens of Anonyx sp. Being able to consume large amounts of food over a short timeframe would be advantageous for a deep-sea scavenger as food falls come rarely and unexpected. There are known adaptations in other species, where the amphipods have expandable stomachs and can swell up to three times their normal size (Shulenberger and Hessler 1974; Thurston 1979). E. gryllus is known to have a rigid exoskeleton (Dahl 1979), so the empty exoskeletons could therefore perhaps be explained by moulting, where an individual moults to get a softer and more expandable body, enabling larger amounts of food to be consumed. This would be, however, a quite risky strategy, as newly moulted individuals would be vulnerable to attacks from both intra- and inter-specific predators. A different explanation might be that the empty exoskeletons actually were eaten individuals, or that they had burst, which was the case in a study by Ingram and Hessler (1983).

\section{Conclusion}

The predominant pigment in all colour stages of both E. gryllus and Anonyx sp. was astaxanthin, which occurred in several forms, probably due to esterification, and which presence was confirmed by measurements of molecular weights from the LC-MS. In addition, by retention times and OD $(\lambda)$ obtained by HPLC, several other carotenoids were identified; E. gryllus contained lutein-like and canthaxanthin-like carotenoids in addition to six unidentified carotenoids, while in Anonyx sp. $\beta, \beta$-carotene, diatoxanthin and canthaxanthin-like carotenoids, as well as two unidentified carotenoids, were found. An increasing amount and diversity of carotenoids as a function of colour intensity was evident in both species, and there was also a correlation between colour intensity and body size. There were indications that growth ceases or slows down at a certain size, while the amount of pigmentation continues to increase. Shifts in wavelength between the colour stages and shifts between the in vivo and in vitro average measurements indicated both intra- and inter-specific differences. Changes in pigment composition are probably affected by both diet and moulting/growth patterns and possibly also by other factors like metabolic pathways or reproduction. Due to the lack of knowledge about these species, future prospective would be to further elucidate their ecophysiology and distribution patterns, as well as general physiology and ecology. 
Acknowledgments The research was funded by The Norwegian University of Science and Technology (NTNU), The University Centre in Svalbard (UNIS) and Svalbard Science Forum. Also thanks to Finlo Cottier from the Scottish Association for Marine Science (SAMS), Kjersti Andresen from Trondheim Biological Station, Per Bruheim at the Department of Biotechnology at NTNU and Malin Daase from the Norwegian Polar Institute.

Open Access This article is distributed under the terms of the Creative Commons Attribution Noncommercial License which permits any noncommercial use, distribution, and reproduction in any medium, provided the original author(s) and source are credited.

\section{References}

Baldwin RJ, Smith KL Jr (1987) Temporal variation in the catch rate, length, color and sex of the necrophagous amphipod, Eurythenes gryllus, from the central and eastern North Pacific. Deep-Sea Res 34:425-439

Berticat O, Nègre-Sadargues G, Castillo R (2000) The metabolism of astaxanthin during the embryonic development of the crayfish Astacus leptodactylus Eschscholtz (Crustacea, Astacidea). Comp Biochem Physiol 127:309-318

Bidigare RR, Ondrusek ME, Kennicutt MC, Iturriaga R, Harvey HR, Hoham RW, Macko SA (1993) Evidence for a photoprotective function for secondary carotenoids of snow algae. J Phycol 29:427-434

Chapelle G, Peck LS (1999) Polar gigantism dictated by oxygen availability. Nature 399:114-115

Charmasson SS, Calmet DP (1987) Distribution of scavenging Lysianassidae amphipods Eurythenes gryllus in the northeast Atlantic: comparison with studies held in the Pacific. Deep Sea Res 34:1509-1523

Cornet S, Biard C, Moret Y (2007) Is there a role for antioxidant carotenoids in limiting self-harming immune response in invertebrates? Biol Lett 3:284-288

Dahl E (1979) Deep-sea carrion feeding amphipods: evolutionary patterns in niche adaptation. OIKOS 33:167-175

Dall W, Smith DM, Moore LE (1995) Carotenoids in the tiger prawn Penaeus esculentus during ovarian maturation. Mar Biol 123:435-441

De Broyer C, Nyssen F, Dauby P (2004) The crustacean scavenger guild in Antarctic shelf, bathyal and abyssal communities. Deep Sea Res II 51:1733-1752

Falk-Petersen S, Mayzaud P, Kattner G, Sargent JR (2009) Lipids and life strategy of Arctic Calanus. Mar Biol Res 5:18-39

Fraser PD, Bramley PM (2004) The biosynthesis and nutritional uses of carotenoids. Prog Lipid Res 43:228-265

Gaillard M, Juillet C, Cézilly F, Perrot-Minnot M (2004) Carotenoids of two freshwater amphipod species (Gammarus pulex and $G$. roeseli) and their common acanthocephalan parasite Polymorphus minutus. Comp Biochem Physiol 139B:129-136

Gilchrist BM, Lee WL (1972) Carotenoid pigments and their possible role in reproduction in the sand crab, Emerita analoga (Stimpson, 1857). Comp Biochem Physiol 42B:263-294

Goodwin TW (1980) Nature and distribution of carotenoids. Food Chem 5:3-13

Grzymski J, Johnsen G, Sakshaug E (1997) The significance of intracellular self-shading on the biooptical properties of brown, red, and green macroalgae. J Phycol 33:408-414

Hairston NG Jr (1976) Photoprotection by carotenoid pigments in the copepod Diaptomus nevadensis. Proc Natl Acad Sci USA 73:971-974
Hargrave BT, Prouse NJ, Phillips GA, Cranford PJ (1994) Meal size and sustenance time in the deep-sea amphipod Eurythenes gryllus collected from the Arctic Ocean. Deep Sea Res 41:14891508

Herring P (1972) Depth distribution of the carotenoid pigments and lipids of some oceanic animals. J Mar Biol Ass UK 52:179-189

Herring P (2002) The biology of the deep ocean. Oxford University Press, New York

Hessler RR, Ingram CL, Yayanos AA, Burnett BR (1978) Scavenging amphipods from the floor of the Philippine Trench. Deep-Sea Res 25:1029-1047

Higuera-Ciapara I, Felix-Valenzuela L, Goycoolea FM (2006) Astaxanthin: a review of its chemistry and applications. Crit Rev Food Sci Nutr 46:185-196

Ingólfsson A, Agnarsson I (1999) Anonyx sarsi: a major unrecognized scavenger and predator in the intertidal zone. J Mar Biol Ass UK 79:1127-1128

Ingram CL, Hessler RR (1983) Distribution and behavior of scavenging amphipods from the central North Pacific. DeepSea Res 30:683-706

Ingram CL, Hessler RR (1987) Population biology of the deep-sea amphipod Eurythenes gryllus: inferences from instar analysis. Deep Sea Res 34:1889-1910

Jeffrey SW, Mantoura RFC, Wright SW (1997) Phytoplankton pigments in oceanography: guidelines to modern methods. UNESCO, Paris

Johnsen S (2005) The red and the black: bioluminescence and the color of animals in the deep Sea. Integr Comp Biol 45:234 246

Katayama T, Hirata K, Chichester CO (1971) The biosynthesis of astaxanthin - IV. The carotenoids in the prawn Penaeus japonicus Bate (Part 1). Bull Jpn Soc Sci Fish 37:614-620

Legeżyńska J (2008) Food resource partitioning among Arctic sublittoral lysianassoid amphipods in summer. Polar Biol 31:663-670

Liñán-Cabello MA, Paniagua-Michel J, Hopkins PM (2002) Bioactive roles of carotenoids and retinoids in crustaceans. Aquac Nutr 8:299-309

Nicol JAC (1958) Observations on luminescence in pelagic animals. J Mar Biol Assoc UK 37:705-752

Obermüller B, Karsten U, Abele D (2005) Response of oxidative stress parameters and sunscreening compounds in Arctic amphipods during experimental exposure to maximal natural UVB radiation. J Exp Mar Biol Ecol 323:100-117

Petit H, Nègre-Sadargues G, Castillo R, Valin S, Trilles J-P (1998) The effects of dietary astaxanthin on the carotenoid pattern of the prawn Penaeus japonicus during postlarval development. Comp Biochem Physiol 119A:523-527

Premke K, Muyakshin S, Klages M, Wegner J (2003) Evidence for long-range chemoreceptive tracking of food odour in deep-sea scavengers by scanning sonar data. J Exp Mar Biol Ecol 285286:283-294

Repeta DJ, Gagosian RB (1984) Transformation reactions and recycling of carotenoids and chlorins in the Peru upwelling region $\left(15^{\circ} \mathrm{S}, 75^{\circ} \mathrm{W}\right)$. Geochim Cosmochim Acta 48:1265-1277

Robison BH (2004) Deep pelagic biology. J Exp Mar Biol Ecol 300:253-272

Rodrìguez F, Chauton M, Johnsen G, Andresen K, Olsen LM, Zapata M (2006) Photoacclimation in phytoplankton: implications for biomass estimates, pigment functionality and chemotaxonomy. Mar Biol 148:963-971

Sainte-Marie B (1992) Foraging of scavenging deep-sea lysiannasoid amphipods. In: Rowe GT, Pariente V (eds) Deep-sea food chains and the global carbon cycle. Kluwer, Texas, pp 105-124

Sainte-Marie B, Lamarche G (1985) The diets of six species of the carrion-feeding lysiannassid amphipod genus Anonyx and their 
relation with morphology and swimming behavior. Sarsia 70:119-126

Schubert N, García-Mendoza E (2008) Photoinhibition in red algal species with different carotenoid profiles. J Phycol 44:1437-1446

Shulenberger E, Hessler RR (1974) Scavenging abyssal benthic amphipods trapped under oligotrophic central North Pacific gyre waters. Mar Biol 28:185-187

Smith CR, Baco AR (2003) Ecology of whale falls at the deep-sea floor. Oceanogr Mar Biol 41:311-354

Smith KL, Baldwin RJ (1984) Vertical distribution of the necrophagous amphipod, Eurythenes gryllus, in the North Pacific: spatial and temporal variation. Deep-Sea Res 31:1179-1196

Stafsnes M, Josefsen K, Kildahl-Andersen G, Valla S, Ellingsen T, Bruheim P (2010) Isolation and characterization of marine pigmented bacteria from Norwegian coastal waters and screening for carotenoids with UVA-blue light absorbing properties. J Microbiol 48:16-23

Steele DH (1979) Zoogeography of the genus Anonyx (Crustacea, Amphipoda). Bull Biol Soc Wash 3:47-53

Stoddart HE, Lowry JK (2004) The deep-sea lysianassoid genus Eurythenes (Crustacea, Amphipoda, Eurytheneidae n. fam.). Zoosystema 26:425-468
Tanaka Y, Matsuguchi H, Katayama T (1976) The biosynthesis of astaxanthin-XVIII. The metabolism of the carotenoids in the prawn, Penaeus japonicus Bate. Bull Jpn Soc Sci Fish 42:197202

Thurston MH (1979) Scavenging abyssal amphipods from the NorthEast Atlantic ocean. Mar Biol 51:55-68

Thurston MH, Petrillo M, Croce ND (2002) Population stucture of the necrophagous amphipod Eurythenes gryllus (Amphipoda: Gammaridea) from the Atacama Trench (south-east Pacific Ocean). J Mar Biol Assoc UK 82:205-211

Vershinin A (1999) Biological functions of carotenoids-diversity and evolution. BioFactors 10:99-104

Werner I, Auel H, Kiko R (2004) Occurrence of Anonyx sarsi (Amphipoda: Lysianassoidea) below Arctic pack ice: an example for cryo-benthic coupling? Polar Biol 27:474-481

Wlodarska-Kowalczuk M, Kendall MA, Weslawski JM, Klages M, Soltwedel T (2004) Depth gradients of benthic standing stock and diversity on the continental margin at a high-latitude ice-free site (off Spitsbergen, $79^{\circ}$ N). Deep-Sea Res I 51:1903-1914 